\title{
Detection and estimation of damage in structures using imperialist competitive algorithm
}

\author{
A. Bagheri, H.R. Razeghi and G. Ghodrati Amiri* \\ Center of Excellence for Fundamental Studies in Structural Engineering, School of Civil Engineering, \\ Iran University of Science \& Technology, Tehran, Iran
}

Received 11 November 2010

Revised 12 February 2011

\begin{abstract}
This paper presents a method for detection and estimation of structural damage on the basis of modal parameters of a damaged structure using imperialist competitive algorithm. The imperialist competitive algorithm was developed over the last few years in an attempt to overcome inherent limitations of traditional optimize method. In this research, imperialist competitive algorithm has been employed due to its favorable performance in detection of structural damages. The performance of the proposed method has been verified through using a benchmark problem provided by the IASC-ASCE Task Group on Structural Health Monitoring and a number of numerical examples. By way of comparison between location and amount of damage obtained from the proposed method and simulation model, it was concluded that the method is sensitive to the location and amount of damage. The results clearly revealed the superiority of the presented method in comparison with energy index method.
\end{abstract}

Keywords: Damage, identification, imperialist competitive algorithm, modal analysis, optimization

\section{Introduction}

Early damage detection in engineering structures such as bridges and towers during their service life has received considerable attention in the literature. Awareness on the location and value of damages may be useful to recognize the structural health conditions.

Damages cause some changes in the physical properties of structures such as stiffness and damping at damaged locations. Consequently, these changes make dynamic characteristics like natural frequencies, mode shapes and damping ratio of the structure to deviate from its initial undamaged condition. The modal analysis method, one of the many nondestructive evaluation methods, is based on the change of modal parameters with a change in the structural properties. Many analytical and experimental studies have been conducted to establish analytical correlations between the damage severity and the modal parameters [1].

The mode shape curvatures are more sensitive to small perturbations than modal displacements, and therefore can also be used to detect damage [2]. Since their estimation from experimental data is very difficult, they are not normally applicable. Shi et al. [3,4] directly used the modal strain energy change for damage detection. Hsu and Loh [5] presented a modified modal strain energy change method and its corresponding iteration process to detect damage to frame structures. Also, Bayissa et al. [6] proposed a damage identification method based on the statistical moments of the energy density function of the vibration responses in the time-scale domain.

\footnotetext{
*Corresponding author. Tel.: +98 21 77240090; Fax: +98 21 77240398; E-mail: ghodrati@iust.ac.ir.
} 
A damage identification method is the modification of structural model matrices such as mass, stiffness, and damping to reproduce as closely as possible the measured dynamic response from the data [1]. Perera and Torres [7] presented a damage detection method based on the changes in frequencies and mode shapes of a beam using genetic algorithm. Further, a frequency response function-based damage detection method using advanced genetic algorithms was proposed by Raich and Liszkai [8].

Imperialist competitive algorithm is a new socio-politically motivated global search strategy that has recently been introduced for dealing with different optimization tasks [9]. This evolutionary optimization strategy has shown great performance in both convergence rate and better global optima achievement [9-12]. Nevertheless, its effectiveness, limitations and applicability in various domains are currently being extensively investigated.

In this research, the damage identification has been formulated as an optimization problem and has been solved using the imperialist competitive algorithm. The efficiency of the method has been validated using numerical examples and the benchmark problem proposed by the IASC-ASCE Task Group on Structural Health Monitoring [13]. Moreover, the performances of method have been evaluated through comparison the obtained results with energy index method presented by Sharifi and Banan [14].

\section{Overview on imperialist competitive algorithm}

The imperialist competitive algorithm is an optimization and search technique based on the socio-political process of imperialism and imperialistic competition as a source of inspiration. Similar to other evolutionary algorithms, this algorithm starts with an initial population. Each individual of the population is called a 'country'. Some of the best countries are selected to be the imperialist states and the rest form the colonies of these imperialists. All the colonies of initial countries are divided among the mentioned imperialists based on their power. The power of each country, the counterpart of fitness value in the genetic algorithm, is inversely proportional to its cost. The imperialist states together with their colonies form some empires [12].

In this algorithm, the goal of optimization is to find an optimal solution in terms of the variables of the problem. We form an array of variable values to be optimized; this array is called 'country'. Each variable in the country can be interpreted as a socio-political characteristic of a country. All the algorithm does is to search for the best country that is the country with the best combination of socio-political characteristics like 'culture', 'language' and 'economical policy'.

The cost of a country is found by evaluation of the cost function $f$ at variables. To start the imperialist competitive algorithm, initial countries of size $N_{\text {Country }}$ is produced. We select $N_{i m p}$ of the most powerful countries to form the empires. The remaining $N_{c o l}$ of the initial countries will be the colonies [9].

To form the initial empires, the colonies are divided among imperialists based on their power. That is, the initial number of colonies of an empire should be directly proportionate to its power. The initial colonies are divided among empires based on their power.

Next, the imperialist states tried to absorb their colonies and make them a part of themselves, this process is pursuing assimilation policy. More precisely, the imperialist states made their colonies to move toward themselves along different socio-political axis such as culture, language and religion. In the imperialist competitive algorithm, this process is modeled by moving all of the colonies toward the imperialist along different optimization axis [10].

Assimilating the colonies by the imperialist states did not result in direct movement of the colonies toward the imperialist. That is, the direction of movement is not necessarily the vector from colony to the imperialist. To model this fact and to increase the ability of searching more area around the imperialist, a random amount of deviation is added to the direction of movement.

In the imperialist competitive algorithm, a colony might reach to a position with lower cost than the imperialist. In this time, the imperialist and the colony change their positions. Then, the algorithm will continue by the imperialist in the new position and the colonies will be assimilated by the imperialist in its new position.

Total power of an empire is mainly affected by the power of imperialist country. However, the power of the colonies of an empire has an effect, albeit negligible, on the total power of that empire.

All empires try to take the possession of colonies of other empires and control them. The imperialistic competition gradually brings about a decrease in the power of weaker empires and an increase in the power of more powerful 
ones. The imperialistic competition is modeled by just picking some of the weakest colonies of the weakest empire and making a competition among all empires to possess these colonies. To start the competition, first, a colony of the weakest empire is chosen and then the possession probability of each empire is found [12].

\section{The damage detection method}

The modal characteristics of a structure without damage are described by the equations:

$$
\left[\mathbf{K}-\omega_{i}^{2} \mathbf{M}\right] \Phi_{i}=0 \quad i=1,2, \ldots, m
$$

where, $\mathbf{M}$ and $\mathbf{K}$ are mass and stiffness matrices, respectively; $\boldsymbol{\omega}_{i}$ is the natural frequency corresponding to mode shape $\Phi_{i}$; and $m$ is the number of structural mode.

The inverse detection of the damage in a structure using modal data requires a forward model dependent on parameters related to the damage quantification and, moreover, as sensitive as possible to changes in the response of the structure.

The damage can be quantified through a scalar variable $d$ whose values are between 0 for the undamaged member of structure and 1 for a rupture member. The damage can be described by a decrease in the stiffness of the element:

$$
\mathbf{K}_{e}^{d}=\left(1-d_{e}\right) \mathbf{K}_{e}
$$

where, $\mathbf{K}_{e}^{d}$ and $\mathbf{K}_{e}$ are the damaged and undamaged local stiffness matrices of the $e$ th element in the finite element method, respectively; and $d_{e}$ is the damage of the $e$ th element.

Also, it is assumed that no change would occur before and after damage in the mass matrix, and accordingly it is applicable to the real problems.

In the finite element method, for a damaged structure the damaged global stiffness matrix is obtained by transformation and assemblage. The damaged local stiffness matrix $\mathbf{K}_{e}^{d}$ is first transformed into $\overline{\mathbf{K}}_{e}^{d}$, which is the damaged element stiffness matrix in the global coordinate system, using the transformation matrix $\mathbf{T}$, by:

$$
\overline{\mathbf{K}}_{e}^{d}=\mathbf{T}^{T} \mathbf{K}_{e}^{d} \mathbf{T}
$$

The damaged element stiffness matrix in the global coordinate system $\overline{\mathbf{K}}_{e}^{d}$ is then expanded into $(p \times p)$ matrix denoted by $\tilde{\mathbf{K}}_{e}^{d}$, where, $p$ is the number of degrees of freedom (DOFs) of the structure. The damaged global stiffness matrix $\mathbf{K}^{d}$ is obtained by summation of $\tilde{\mathbf{K}}_{e}^{d}$ for all elements:

$$
\mathbf{K}^{d}=\sum_{e=1}^{n} \tilde{\mathbf{K}}_{e}^{d}
$$

where, $n$ is the total number of finite elements in structure.

Thus, Eq. (1) for a damaged structure can be written as follows:

$$
\left[\mathbf{K}^{d}-\left(\omega_{i}^{d}\right)^{2} \mathbf{M}\right] \Phi_{i}^{d}=0 \quad i=1,2, \ldots, m
$$

where, $\boldsymbol{\omega}_{i}^{d}$ and $\Phi_{i}^{d}$ are the $i$ th natural frequency and the $i$ th mode shape of the damaged structure, respectively.

If the measured modal results are substituted in Eq. (5), it is possible to consider the problem of the structural damage detection as an optimization problem. Due to the complexities involved in the problem of damage detection, traditional methods seem not to be appropriate to solve such optimization problems. While new optimization and search techniques such as imperialist competitive algorithm can be applied to the optimization problems.

The imperialist competitive algorithm approach attempts to find the best solution to a given problem by minimizing a cost function. Therefore, the key point in a minimization problem is the cost function. This function is used to provide a measure of how empires have performed in the problem domain. In the case of a minimization problem, the fit empires will have the lowest numerical value of the associated cost function.

In this method, imperialist competitive algorithm has been used to determine the damage of structural elements through optimization of cost function. The general expression for the cost function is:

$$
\text { Cost Function }=f\left(d_{1}, d_{2}, \ldots, d_{n}\right)
$$


To construct the cost function, all kinds of the structure output which are highly sensitive to the damage variables should be used.

In the event of substituting the measured modal parameters of the damaged structure in Eq. (5), vectors can be defined as follows:

$$
\mathbf{E}_{i}=\left[\mathbf{K}^{d}-\left(\omega_{i}^{m}\right)^{2} \mathbf{M}\right] \Phi_{i}^{m} \quad i=1,2, \ldots, k, \quad e=1,2, \ldots, n
$$

where, $\boldsymbol{\omega}_{i}^{m}$ and $\Phi_{i}^{m}$ are the $i$ th natural frequency and the $i$ th mode shape from measurements, respectively; and $k$ is total number of mode shape for damage detection.

Therefore, the problem of damage detection can be formulated as an optimization problem. The objective is to minimize the following cost function:

$$
f=\sqrt{\sum_{i=1}^{k}\left(\sum_{j=1}^{p}\left(\mathbf{E}_{i}\right)^{2}\right)} i=1,2, \ldots, k
$$

where, $p$ is the number of DOFs of the structure.

In order to solve this equation, we select an array of random points on the cost function. This array is defined as follow:

$$
\text { Country }=\left[d_{1}, d_{2}, \ldots, d_{n}\right]
$$

The cost of a country is found by evaluation of the cost function:

$$
\text { cost }=f(\text { Country })
$$

To start the optimization algorithm, initial countries of size $N_{\text {Country }}$ are produced. The selection of this number is based on trial and error and the amount of this number depends on the number of dimensions of optimization problem. We select $N_{i m p}$ of the most powerful countries to form the empires. The remaining $N_{c o l}$ of the initial countries will be the colonies each of which belongs to an empire.

To form the initial empires, the initial number of colonies of an empire should be directly proportionate to its normalized power. The normalized cost of an imperialist is defined by:

$$
C_{j}=c_{j}-\max _{i}\left\{c_{i}\right\}
$$

where, $c_{j}$ is the cost of the $j$ th imperialist and $C_{j}$ is its normalized cost. The normalized power of each imperialist is:

$$
p_{j}=\left|\frac{C_{j}}{\sum_{i=1}^{N_{i m p}} C_{i}}\right|
$$

Then, the initial number of colonies of the $j$ th empire will be [9]:

$$
N . C \cdot j=\operatorname{round}\left\{p_{j} . N_{c o l}\right\}
$$

To divide the colonies, N.C.j of the colonies are randomly chosen and given to the $j$ th imperialist.

In the imperialist competitive algorithm, the assimilation policy is modeled by moving all the colonies toward the imperialist. This movement is shown in Fig. 1 in which a colony moves toward the imperialist by $x$ units. The new position of the colony is shown in a darker color. The direction of the movement is the vector from the colony to the imperialist. In this figure, $x$ is a random variable with uniform distribution. Then:

$$
x \sim U(0, \beta \times d)
$$

where, $\beta$ is a number greater than one and $d$ is the distance between the colony and the imperialist state. $\beta>1$ causes the colonies to get closer to the imperialist state from both sides [12].

If there is a colony in an empire which has lower cost than that of the imperialist, exchange the positions of that colony and the imperialist, and then compute the total cost of all empires. 


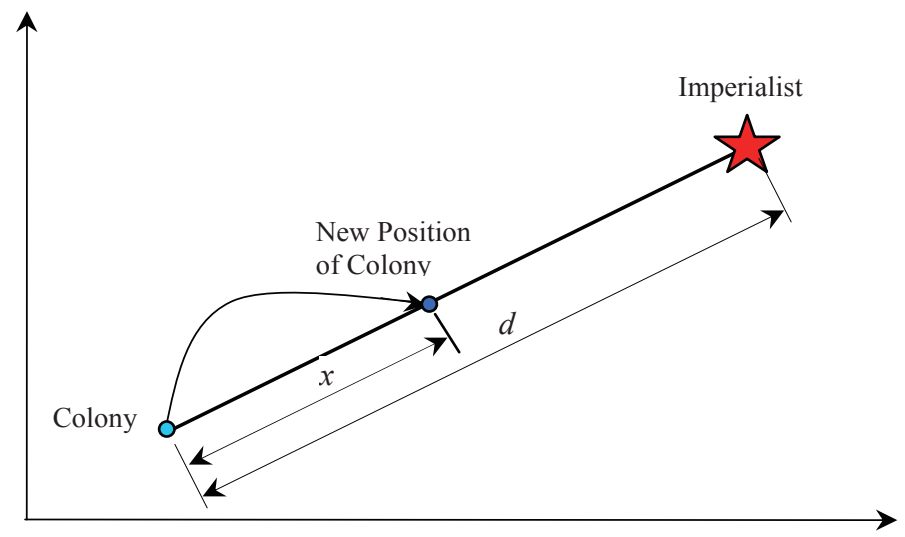

Fig. 1. Movement of colonies toward their relevant imperialist.

The total power of an empire depends on both the power of the imperialist country and the power of its colonies. This fact can be modeled by defining the total power of an empire as the power of imperialist country plus a percentage of mean power of its colonies. Therefore, the total cost of an empire is determined by:

$$
T . C \cdot j=f\left(\text { Imprialist }_{j}\right)+\xi \frac{\sum_{i=1}^{N . C \cdot n} f\left({\text { Colonies of } \left.\text { empire }_{i}\right)}^{N . C \cdot j}\right.}{N \cdot j}
$$

where $\xi$ is a positive small number.

Next, pick the weakest colony (colonies) from the weakest empires and give it (them) to the empire that has the most likelihood to possess it (imperialistic competition). To start the competition, the normalized total cost of an empire is obtained:

$$
N . T . C \cdot{ }_{j}=T . C \cdot{ }_{j}-\max _{i}\{T . C \cdot i\}
$$

where N.T.C. $j$ is the normalized total cost of $j$ th empire. The normalized total cost, the possession probability of each empire is given by:

$$
p_{p_{j}}=\left|\frac{N \cdot T \cdot C \cdot j}{\sum_{i=1}^{N_{i m p}} N \cdot T \cdot C \cdot i}\right|
$$

To divide the mentioned colonies among empires, vector $\mathbf{P}$ is formed as follows:

$$
\mathbf{P}=\left[p_{p_{1}}, p_{p_{2}}, \ldots, p_{p_{n}}\right]
$$

Then, the vector $\mathbf{R}$ with the same size as $\mathbf{P}$ whose elements are uniformly distributed random numbers is created. Next, vector $\mathbf{D}$ is formed by subtracting $\mathbf{R}$ from $\mathbf{P}$.

$$
\mathbf{D}=\mathbf{P}-\mathbf{R}
$$

Referring to vector $\mathbf{D}$, the mentioned colony is handed to an empire whose relevant index in $\mathbf{D}$ is maximized.

Finally, eliminate the powerless empires and if there is only one empire left, stop, if not go to assimilation. The algorithm progresses to reach an optimum solution for the studied problem. Figure 2 shows the flowchart of the proposed method for estimation and detection of the damage using imperialist competitive algorithm.

\section{The validation of the proposed method}

In order to investigate the validation of the proposed method for structural damage detection, it was applied to a simple example, the first phase of IASC-ASCE benchmark structure and two numerical examples such as a three-story plane frame and a plane truss. 


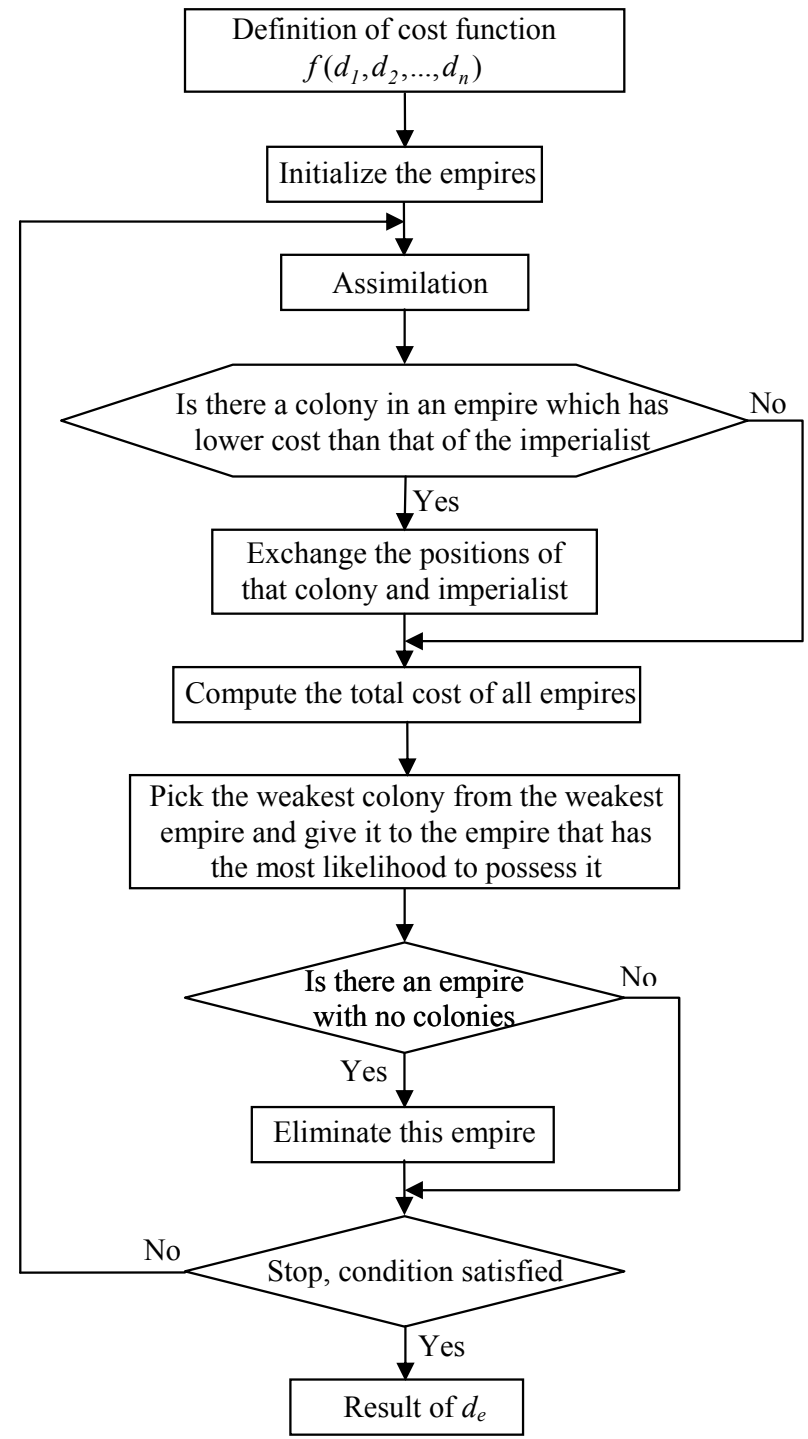

Fig. 2. Flowchart of the damage detection method using imperialist competitive algorithm.

\subsection{Simple example}

The first numerical example is a two-story shear frame with the following physical properties:

$$
\begin{aligned}
& M_{1}=M_{2}=10 \mathrm{~kg} \\
& K_{1}=K_{2}=100 \mathrm{~N} / \mathrm{m}
\end{aligned}
$$

In the model, damage was considered in the first story with $10 \%$ reduction in stiffness.

The mode shapes and natural frequencies of the frame are:

$$
\begin{aligned}
& \omega_{1}=1.88 \mathrm{rad} / \mathrm{sec}, \quad \omega_{2}=5.05 \mathrm{rad} / \mathrm{sec} \\
& \Phi_{1}=\left[\begin{array}{l}
-0.647 \\
-1
\end{array}\right], \quad \Phi_{2}=\left[\begin{array}{l}
-1 \\
0.647
\end{array}\right]
\end{aligned}
$$

The damaged stiffness of each story is determined using Eq. (2): 
$K_{1}^{d}=\left(1-d_{1}\right) 100, \quad K_{2}^{d}=\left(1-d_{2}\right) 100$

Also, the global mass and damaged stiffness of the frame can be expressed:

$$
\mathbf{M}=\left[\begin{array}{cc}
10 & 0 \\
0 & 10
\end{array}\right], \quad \mathbf{K}^{d}=\left[\begin{array}{cc}
K_{1}^{d}+K_{2}^{d}-K_{2}^{d} \\
-K_{2}^{d} & K_{2}^{d}
\end{array}\right]
$$

In this example, the first mode shape of the frame is used for damage detection. Thus, based on Eq. (7) the vector $\mathbf{E}_{1}$ is:

$$
\begin{aligned}
& \mathrm{E}_{1}=\left(\left[\begin{array}{cc}
10 & 0 \\
0 & 10
\end{array}\right]-1.88^{2}\left[\begin{array}{cc}
K_{1}^{d}+K_{2}^{d}-K_{2}^{d} \\
-K_{2}^{d} & K_{2}^{d}
\end{array}\right]\right)\left[\begin{array}{c}
-0.647 \\
-1
\end{array}\right] \\
& \mathrm{E}_{1}=\left[\begin{array}{c}
-6.46+64.658 d_{1}-35.341 d_{2} \\
35.341 d_{2}
\end{array}\right]
\end{aligned}
$$

The cost function was determined via Eq. (8):

$$
f=\sqrt{\left(-6.46+64.658 d_{1}-35.341 d_{2}\right)^{2}+\left(35.341 d_{2}\right)^{2}}
$$

For optimization of the cost function, the selected parameters of the imperialist competitive algorithm are:

$$
N_{\text {Country }}=5, \quad N_{\text {imp }}=2, \quad N_{\text {col }}=N_{\text {Country }}-N_{\text {imp }}=3
$$

Randomly, the array of initial countries was produced:

$$
\begin{aligned}
& \text { Country }_{1}=\left[\begin{array}{ll}
d_{1} & d_{2}
\end{array}\right]=\left[\begin{array}{ll}
0.045 & 0.120
\end{array}\right] \\
& \text { Country }_{2}=\left[\begin{array}{ll}
0.118 & 0.256
\end{array}\right] \\
& \text { Country }_{3}=\left[\begin{array}{ll}
0.840 & 0.949
\end{array}\right] \\
& \text { Country }_{4}=\left[\begin{array}{ll}
0.885 & 0.572
\end{array}\right] \\
& \text { Country }_{5}=\left[\begin{array}{ll}
0.410 & 0.990
\end{array}\right]
\end{aligned}
$$

Then, the cost of countries was obtained by the cost function:

$$
\begin{aligned}
c_{1} & =\sqrt{(-6.46+64.658 \times 0.045-35.341 \times 0.12)^{2}+(35.341 \times 0.12)^{2}} \\
c_{2} & =12.00, \quad c_{3}=36.46, \quad c_{4}=36.62, \quad c_{5}=38.04
\end{aligned}
$$

The countries with the minimum cost are selected as imperialists. Therefore, the Country ${ }_{1}$ and Country f were selected as Imperialists ${ }_{1}$ and Imperialists 2 , respectively. In addition, the remained initial Country ${ }_{3}$, Country ${ }_{4}$ and Country $_{5}$ are Colony $_{1}$, Colony 2 and Colony ${ }_{3}$, respectively.

Based on Eq. (11) the normalized cost of any imperialist is:

$$
C_{1}=8.87-12=-3.13, C_{2}=12-12=0
$$

The normalized power of each imperialist is:

$$
p_{1}=\left|\frac{-3.13}{-3.13}\right|=1, \quad p_{2}=\left|\frac{0}{-3.13}\right|=0
$$

Then, the initial number of colonies of the empires was obtained:

$$
\begin{aligned}
& N . C \cdot{ }_{1}=\operatorname{round}\left\{p_{1} \times N_{\text {col }}\right\}=\operatorname{round}\{1 \times 3\}=3 \\
& N . C \cdot 2=\operatorname{round}\left\{p_{2} \times N_{\text {col }}\right\}=\operatorname{round}\{0 \times 3\}=0
\end{aligned}
$$

Next, the distances between the colonies and the imperialists were calculated for estimation of the new positions of the colonies. The distance between Colony ${ }_{1}$ and Imperialist ${ }_{1}$ is: 


$$
\begin{aligned}
& d=\sqrt{\left(d_{1 \text { Imperialist } 1}-d_{1} \text { Colonyl }\right)^{2}+\left(d_{2} \text { Imperialist1 }-d_{2} \text { Colonyl }\right)^{2}} \\
& d=\sqrt{(0.045-0.84)^{2}+(0.12-0.949)^{2}}=1.148
\end{aligned}
$$

Also, the distance between Colony ${ }_{2}$ and Imperialist ${ }_{1}$ is 0.954 , and the distance between Colony and Imperialist $_{1}$ is 0.943 . Therefore, $x$ units for estimation of the new positions of colonies are:

$$
\begin{aligned}
& x_{1} \sim U(0,2 \times 1.148)=0.482 \\
& x_{2} \sim U(0,2 \times 0.954)=0.149 \\
& x_{3} \sim U(0,2 \times 0.954)=0.490
\end{aligned}
$$

Thus, the new positions of colonies are:

$$
\begin{aligned}
& \text { colony }_{1}=\text { countr }_{3}-x_{1} \times[\cos (\theta) \sin (\theta)] \\
& \text { colony }_{1}=\left[\begin{array}{ll}
0.840 & 0.949
\end{array}\right]-0.482 \times[\cos (46.20) \sin (46.20)]=\left[\begin{array}{ll}
0.506 & 0.601
\end{array}\right] \\
& \text { colony }_{2}=\left[\begin{array}{ll}
0.885 & 0.572
\end{array}\right]-0.149 \times[\cos (28.28) \sin (28.28)]=\left[\begin{array}{lll}
0.753 & 0.501
\end{array}\right] \\
& \text { colony }_{3}=\left[\begin{array}{ll}
0.410 & 0.990
\end{array}\right]-0.490 \times[\cos (67.24) \sin (67.24)]=\left[\begin{array}{lll}
0.220 & 0.538
\end{array}\right]
\end{aligned}
$$

Then, the cost of colonies was obtained by the cost function:

$$
\begin{aligned}
& f\left(\text { colony }_{1}\right)=21.82 \\
& f\left(\text { colony }_{2}\right)=30.24 \\
& f\left(\text { colon }_{3}\right)=22.09
\end{aligned}
$$

Therefore, the total cost of an empire was determined:

$$
\begin{aligned}
& \text { T.C. }{ }_{1}=8.87+0.02 \frac{21.82+30.24+22.09}{3}=9.36 \\
& \text { T.C. } 2=12.0+0=12.0
\end{aligned}
$$

The normalized total cost of an empire was obtained for the competition:

$$
\begin{aligned}
& \text { N.T.C. }{ }_{1}=9.36-12=2.64 \\
& \text { N.T.C. } 2=9.36-9.36=0
\end{aligned}
$$

Based on Eq. (17) the normalized total costs are:

$$
\begin{aligned}
& p_{p_{1}}=\left|\frac{-2.64}{-2.64}\right|=1 \\
& p_{p_{2}}=\left|\frac{0}{-2.64}\right|=0
\end{aligned}
$$

To divide the mentioned colonies among empires, vector $\mathbf{P}$ was obtained:

$$
\mathbf{P}=\left[\begin{array}{ll}
1 & 0
\end{array}\right]
$$

Then, the vector $\mathbf{R}$ with the same size as vector $\mathbf{P}$ whose are random numbers and uniformly distributed, was created. Next, vector $\mathbf{D}$ was determined:

$$
\mathbf{D}=\mathbf{P}-\mathbf{R}=\left[\begin{array}{ll}
1 & 0
\end{array}\right]-[0.610 .86]=[0.59-0.86]
$$

Referring to vector $\mathbf{D}$, the mentioned colonies were handed to Empire 1.

Finally, the algorithm obtained an optimum solution of $d_{1}=0.099$ and $d_{2}=0.0$ for the problem after 20 iterations. 


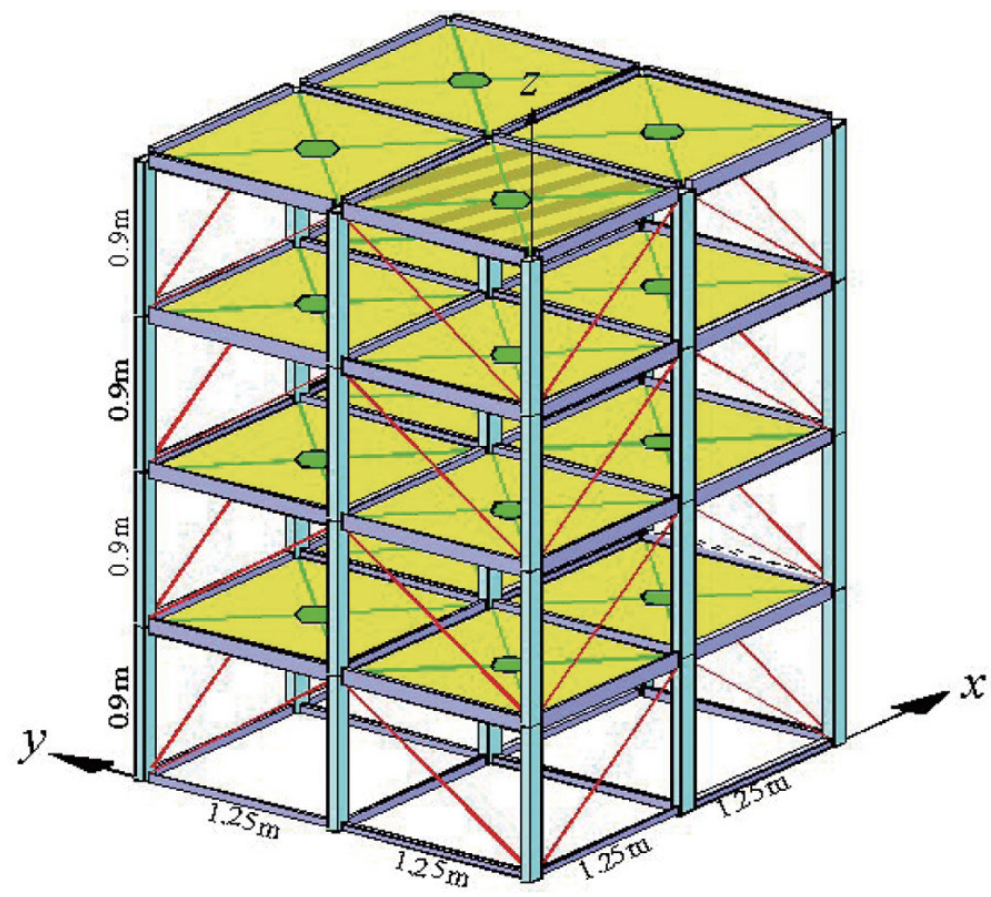

Fig. 3. Geometry of the benchmark structure [16].

\subsection{IASC-ASCE benchmark structure}

The benchmark structure is a four-story steel frame, two-bay by two-bay and quarter-scale model structure constructed in the Earthquake Engineering Research Laboratory at the University of British Colombia. Geometry of the benchmark structure is shown in Fig. 3. Details of the first phase of IASC-ASCE benchmark problem was presented by Johnson et al. [15] also are available on IASC-ASCE Structural Health Monitoring Task Group web site [16].

The proposed method was applied to case 1 of this phase benchmark problem, and the finite element model of the 12 DOF shear building model is used. In this case, the five following damage patterns have been considered:

1. All of the braces of the first story are broken

2. All of the braces of the first and third stories are broken

3. One brace of the first story is broken

4. One brace at the first and third stories is broken

5. $1 / 3$ of area of one brace at the first story is cut

For each damage pattern, the mass and horizontal story stiffnesses are illustrated in Table 1.

Damage in the structures can be determined using the proposed method which employs the imperialist competitive algorithm. The presented method starts with a random initial population of countries. The cost of each solution is evaluated by computing the cost function. Then, the assimilation exchange the positions of that colony and the imperialist, and imperialistic competition are applied to obtain the solution to the problem. The following parameters of imperialist competitive algorithm are appropriate and adopted in this example: initial population of countries $=$ 50 ; initial population of imperialist $=5$; and maximum number of iterations $=500$. Similar to other evolutionary algorithms, the imperialist competitive algorithm is an iterative algorithm. Based on the algorithm calculation, it achieves optimization of function in the each step and the algorithm stops in the maximum iteration steps.

The convergence curves for five damage patterns are shown in Fig. 4. The results of the application of the proposed method to the benchmark structure are cited in Table 2. The structural damage was detected and estimated within different level of damage. The results revealed that there is a good agreement between the actual and estimated damage of the benchmark structure. 
Table 1

Mass and horizontal story stiffness (MN/m) of undamaged and damaged 12 DOF model

\begin{tabular}{lcccccrrr}
\hline Story & DOF & Mass & Undamaged & Pattern (1) & Pattern (2) & Pattern (3) & Pattern (4) & Pattern (5) \\
\cline { 2 - 8 } & & $(\mathrm{kg})$ & stiffness & Stiffness & Stiffness & Stiffness & Stiffness & Stiffness \\
\hline 1 & $\mathrm{x}$ & 3452.4 & 106.60 & 58.37 & 58.37 & 106.60 & 106.60 & 106.60 \\
1 & $\mathrm{y}$ & 3452.4 & 67.90 & 19.67 & 19.67 & 55.84 & 55.84 & 63.88 \\
1 & $\theta_{z}$ & 3819.4 & 232.00 & 81.32 & 81.32 & 213.12 & 213.12 & 225.71 \\
2 & $\mathrm{x}$ & 2652.4 & 106.60 & 106.60 & 106.60 & 106.60 & 106.60 & 106.60 \\
2 & $\mathrm{y}$ & 2652.4 & 67.90 & 67.90 & 67.90 & 67.90 & 67.90 & 67.90 \\
2 & $\theta_{z}$ & 2986.1 & 232.00 & 232.00 & 232.00 & 232.00 & 232.00 & 232.00 \\
3 & $\mathrm{x}$ & 2652.4 & 106.60 & 106.60 & 58.37 & 106.60 & 94.54 & 106.60 \\
3 & $\mathrm{y}$ & 2652.4 & 67.90 & 67.90 & 19.67 & 67.90 & 67.90 & 67.90 \\
3 & $\theta_{z}$ & 2986.1 & 232.00 & 232.00 & 81.32 & 232.00 & 213.12 & 232.00 \\
4 & $\mathrm{x}$ & 1809.9 & 106.60 & 106.60 & 106.60 & 106.60 & 106.60 & 106.60 \\
4 & $\mathrm{y}$ & 1809.9 & 67.90 & 67.90 & 67.90 & 67.90 & 67.90 & 67.90 \\
4 & $\theta_{z}$ & 2056.9 & 232.00 & 232.00 & 232.00 & 232.00 & 232.00 & 232.00 \\
\hline
\end{tabular}

Table 2

The obtained results of damage detection for the benchmark structure (\%)

\begin{tabular}{|c|c|c|c|c|c|c|c|c|c|c|c|}
\hline \multirow[t]{2}{*}{ Story } & \multirow[t]{2}{*}{ DOF } & \multicolumn{2}{|c|}{ Pattern (1) } & \multicolumn{2}{|c|}{ Pattern (2) } & \multicolumn{2}{|c|}{ Pattern (3) } & \multicolumn{2}{|c|}{ Pattern (4) } & \multicolumn{2}{|c|}{ Pattern (5) } \\
\hline & & Estimated & Actual & Estimated & Actual & Estimated & Actual & Estimated & Actual & Estimated & Actual \\
\hline 1 & $\mathrm{x}$ & 45.23 & 45.24 & 45.24 & 45.24 & 0 & 0 & 0 & 0 & 0 & 0 \\
\hline 1 & y & 71.03 & 71.03 & 71.03 & 71.03 & 17.75 & 17.76 & 17.76 & 17.76 & 5.91 & 5.92 \\
\hline 1 & $\theta_{z}$ & 64.96 & 64.95 & 64.96 & 64.95 & 8.14 & 8.14 & 8.14 & 8.14 & 2.71 & 2.71 \\
\hline 2 & $\mathrm{x}$ & 0 & 0 & 0 & 0 & 0 & 0 & 0 & 0 & 0 & 0 \\
\hline 2 & $\mathrm{y}$ & 0 & 0 & 0 & 0 & 0 & 0 & 0 & 0 & 0 & 0 \\
\hline 3 & $\mathrm{y}$ & 0 & 0 & 71.03 & 71.03 & 0 & 0 & 0 & 0 & 0 & 0 \\
\hline 3 & $\theta_{z}$ & 0 & 0 & 64.96 & 64.95 & 0 & 0 & 8.14 & 8.14 & 0 & 0 \\
\hline 4 & $\mathrm{x}$ & 0 & 0 & 0 & 0 & 0 & 0 & 0 & 0 & 0 & 0 \\
\hline 4 & $\mathrm{y}$ & 0 & 0 & 0 & 0 & 0 & 0 & 0 & 0 & 0 & 0 \\
\hline 4 & $\theta_{z}$ & 0 & 0 & 0 & 0 & 0 & 0 & 0 & 0 & 0 & 0 \\
\hline
\end{tabular}

Table 3

Comparison of the results of the methods for damage detection of the benchmark structure (\%)

\begin{tabular}{lccccccc}
\hline Story & DOF & \multicolumn{3}{c}{ Damage pattern (1) } & \multicolumn{3}{c}{ Damage pattern (2) } \\
\cline { 3 - 7 } & & $\begin{array}{c}\text { Presented } \\
\text { method }\end{array}$ & $\begin{array}{c}\text { Energy index } \\
\text { Method [14] }\end{array}$ & Actual & $\begin{array}{c}\text { Presented } \\
\text { method }\end{array}$ & $\begin{array}{c}\text { Energy index } \\
\text { Method [14] }\end{array}$ & Actual \\
\hline 1 & $\mathrm{x}$ & 45.23 & 41.81 & 45.24 & 45.24 & 41.98 & 45.24 \\
1 & $\mathrm{y}$ & 71.03 & 66.26 & 71.03 & 71.03 & 69.48 & 71.03 \\
2 & $\mathrm{x}$ & 0 & 0 & 0 & 0 & 0 & 0 \\
2 & $\mathrm{y}$ & 0 & 0 & 0 & 0 & 0 & 0 \\
3 & $\mathrm{x}$ & 0 & 0 & 0 & 45.24 & 45.13 & 45.24 \\
3 & $\mathrm{y}$ & 0 & 0 & 0 & 71.03 & 69.5 & 71.03 \\
4 & $\mathrm{x}$ & 0 & 0 & 0 & 0 & 0 & 0 \\
4 & $\mathrm{y}$ & 0 & 0 & 0 & 0 & 0 & 0 \\
\hline
\end{tabular}

Furthermore, Table 3 provides comparison between the obtained results from the presented method in this paper and energy index method proposed by Sharifi and Banan [14]. As it is shown, the damages obtained by the proposed model are closer to actual damages compared to the energy index method.

Finally, it can be concluded that this damage identification method is much more sensitive to location and value of damage. This is due to the use of imperialist competitive algorithm in the method for optimization of cost function.

\subsection{Three-story plane steel frame}

Consider a three-story plane steel frame in which the finite-element model consists of nine elements (six columns and three beams) and six free nodes, as shown in Fig. 5. For the steel frame considered, the material properties of 

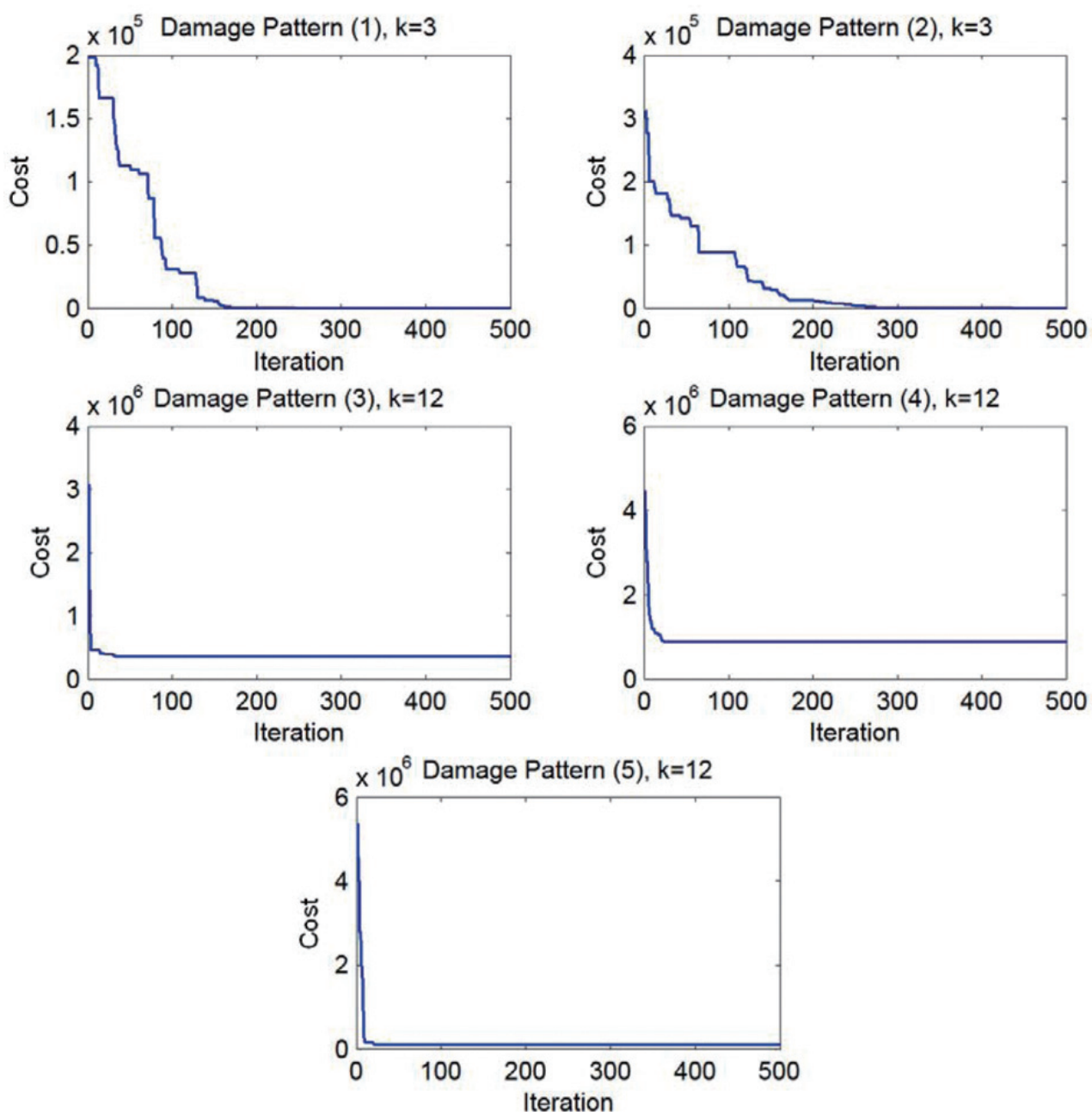

Fig. 4. Convergence curves for five damage patterns of the benchmark structure.

the steel include Young's modulus of $E=200 \mathrm{GPa}$, mass density of $\rho=7850 \mathrm{~kg} / \mathrm{m}^{3}$. The mass per unit length, moment of inertia, and cross-sectional area of the columns are: $m=117.75 \mathrm{~kg} / \mathrm{m}, \mathrm{I}=3.3 \times 10^{-4} \mathrm{~m}^{4}$ and $\mathrm{A}=1.5$ $\times 10^{-2} \mathrm{~m}^{2}$, respectively; for the beams are: $m=4000 \mathrm{~kg} / \mathrm{m}, \mathrm{I}=3.69 \times 10^{-4} \mathrm{~m}^{4}$ and $\mathrm{A}=1.52 \times 10^{-2} \mathrm{~m}^{2}$.

In the finite element model, the damage is represented as the elements with reduction in stiffness. In order to determine damage detection, two different patterns from the aspect of number and location of damage were considered.

In the first pattern, a single damage was considered in member 2 with $10 \%$ reduction in stiffness. In this example, the parameters of imperialist competitive algorithm are: initial population of countries $=50$; initial population of imperialist $=5$; and maximum number of iterations $=500$. The selection of these parameters is based on trial and error and the amounts of the selected numbers depend on the number of elements in the structure. A chose for selection of the number of imperialists is about 0.1 of the number of countries. Also, the maximum number of iterations was selected based on the required accuracy in the optimization. For other damage detection problem, the amounts of these parameters should be obtained based on trial and error.

Convergence curves, and values and location of damage of this pattern with different numbers of the mode shapes and various levels of noise in the modal data are shown in Figs 6 and 7, respectively. Parameter $k$ in the figures is the number of mode shape for damage detection problem. The results demonstrate the capability of the proposed method to find the damage in the frame. 


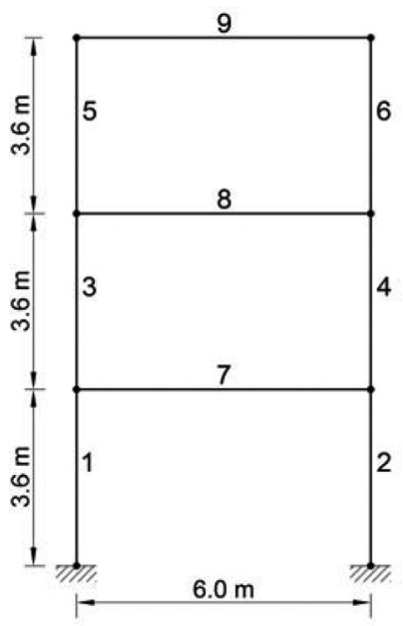

Fig. 5. Three-story plane steel frame with finite-element model.
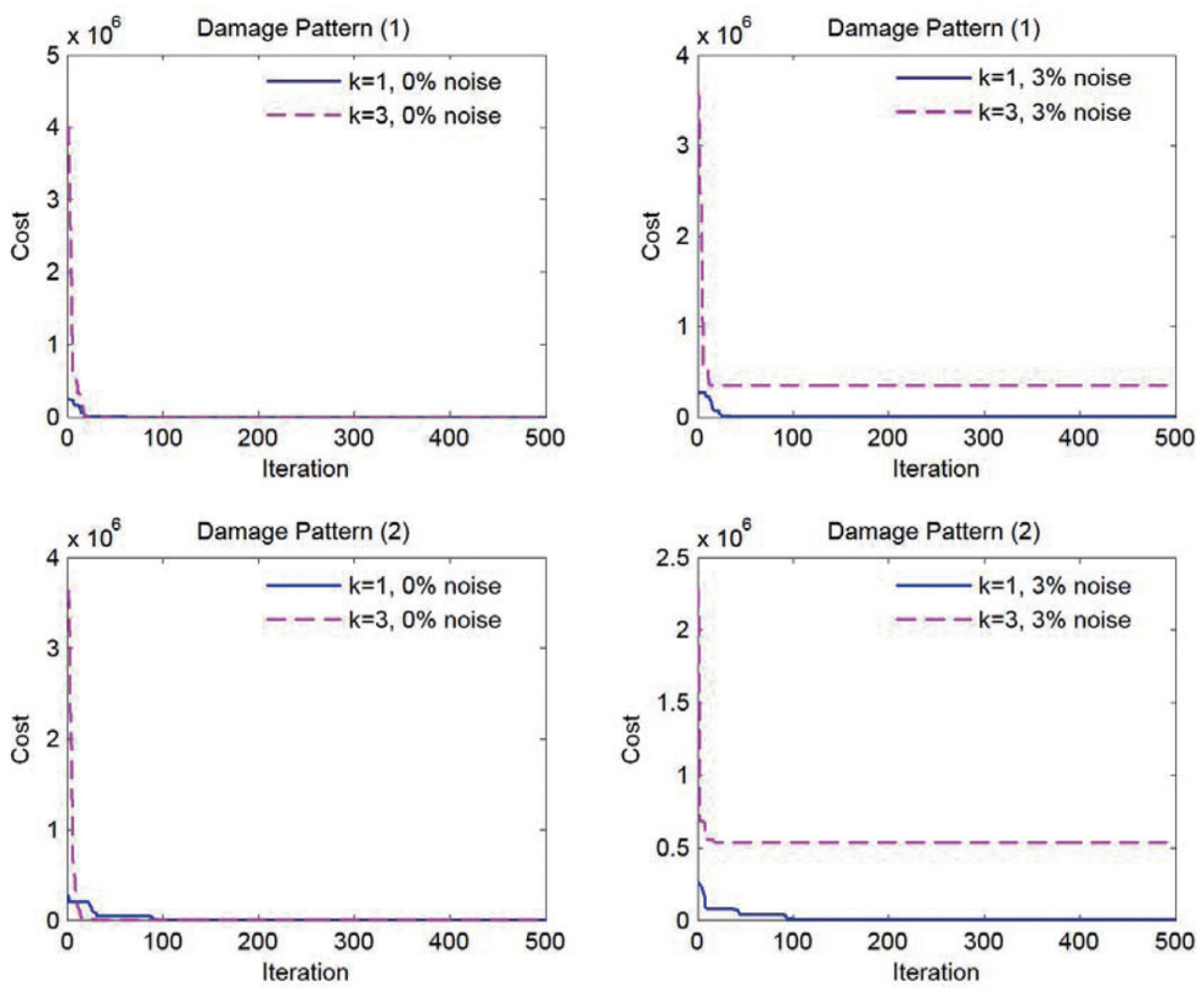

Fig. 6. Convergence curves for two damage patterns of the three-story plane steel frame.

In the second pattern, two damages were considered in the frame. The first damage was at the member 2 with $10 \%$ damage and the second damage is the member 8 with $5 \%$ damage. The convergence curve of this pattern with different numbers of the mode shapes are shown in Fig. 6. For this pattern, the results of damage identification in various numbers of the mode shapes are shown in Fig. 7. Also, in this pattern the locations of damages in frame are identified using the proposed method. 

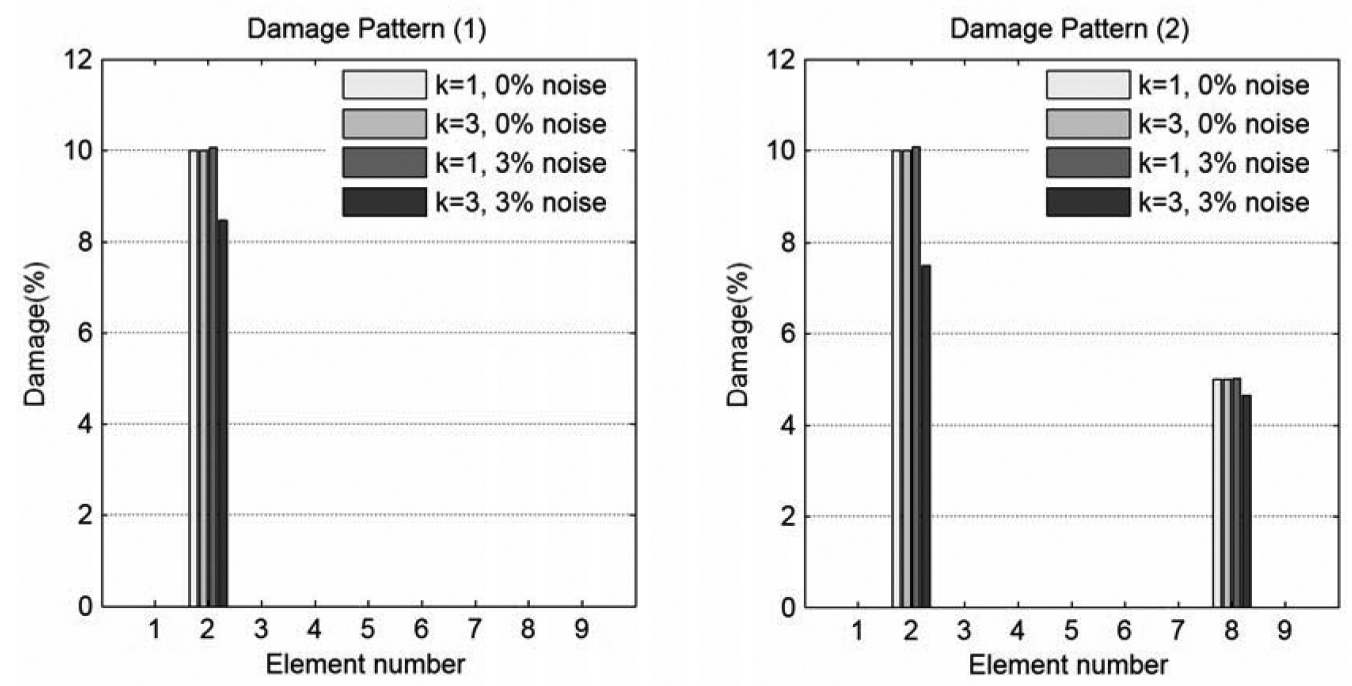

Fig. 7. Results of damage identification for two damage patterns of the three-story plane steel frame.

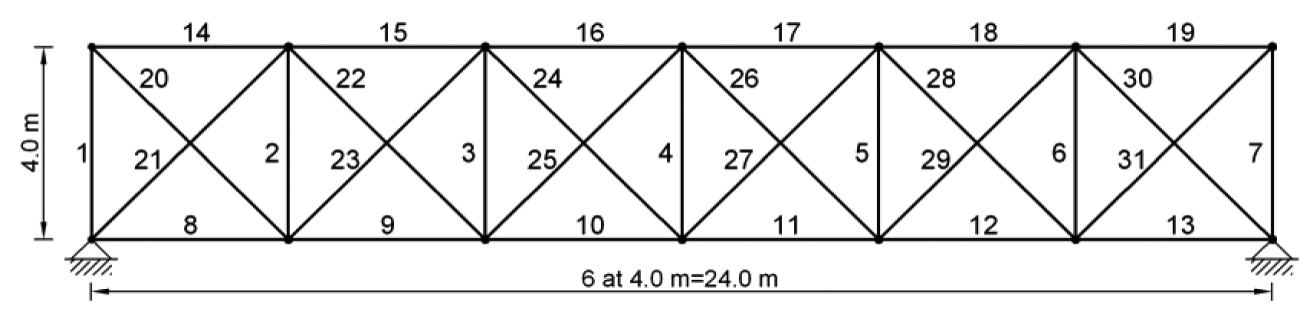

Fig. 8. Plane steel truss with finite-element model.

\subsection{Plane steel truss}

Consider a plane steel truss as shown in Fig. 8. The finite-element truss model consists of 31 members (twelve horizontal elements, seven vertical elements and twelve diagonal elements), 21 free nodes, where each node has two DOFs. The structural parameters, for the top horizontal elements are: $m=117.75 \mathrm{~kg} / \mathrm{m}$, and A $=1.5 \times 10^{-2} \mathrm{~m}^{2}$; for the bottom horizontal elements are: $m=4000 \mathrm{~kg} / \mathrm{m}$ and $\mathrm{A}=1.5 \times 10^{-2} \mathrm{~m}^{2}$; for the vertical elements are: $m=$ $62.80 \mathrm{~kg} / \mathrm{m}$ and $\mathrm{A}=0.8 \times 10^{-2} \mathrm{~m}^{2}$; and for the diagonal elements are: $m=78.50 \mathrm{~kg} / \mathrm{m}$ and A $=1.0 \times 10^{-2} \mathrm{~m}^{2}$.

In this case, the two following damage patterns were considered:

1. The stiffness of members 5, 9 and 30 are reduced by $20 \%$.

2. The stiffness of members 5 and 17 are reduced by $30 \%$ and the stiffness of members 9 and 30 are reduced by $20 \%$.

The proposed method was applied to detect the damage in the plane truss. The parameters of imperialist competitive algorithm are appropriate and adopted in this example: initial population of countries $=100$; initial population of imperialist $=10$; and maximum number of iterations $=1000$. Based on the selected parameters, the cost functions in this example have reached to the global minimum point. In addition, the obtained results for damage detection present a good agreement between the actual and estimated damages in the structure. Therefore, the selected parameters are feasible for the optimization problem. The convergence curves for two damage patterns are illustrated in Fig. 9. Figure 10 shows the capability of the proposed method for detection of damage in the truss for different levels of noise in the modal data. The results indicated that the proposed method can be characterized as a robust and viable method for damage detection in truss structures. 

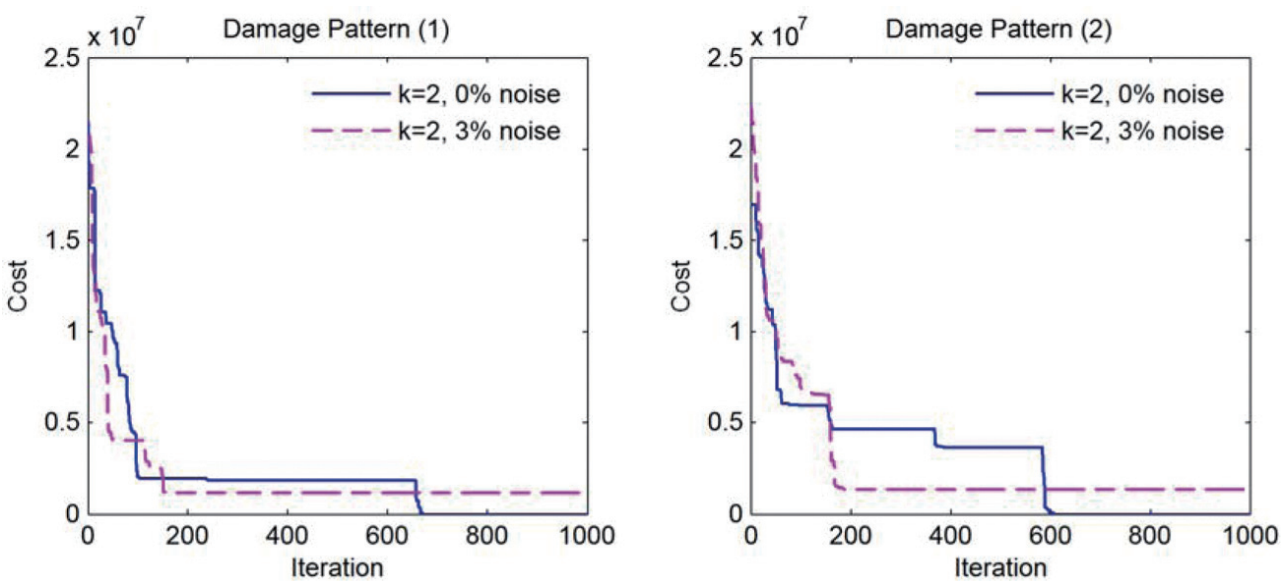

Fig. 9. Convergence curves for two damage patterns of the plane steel truss.
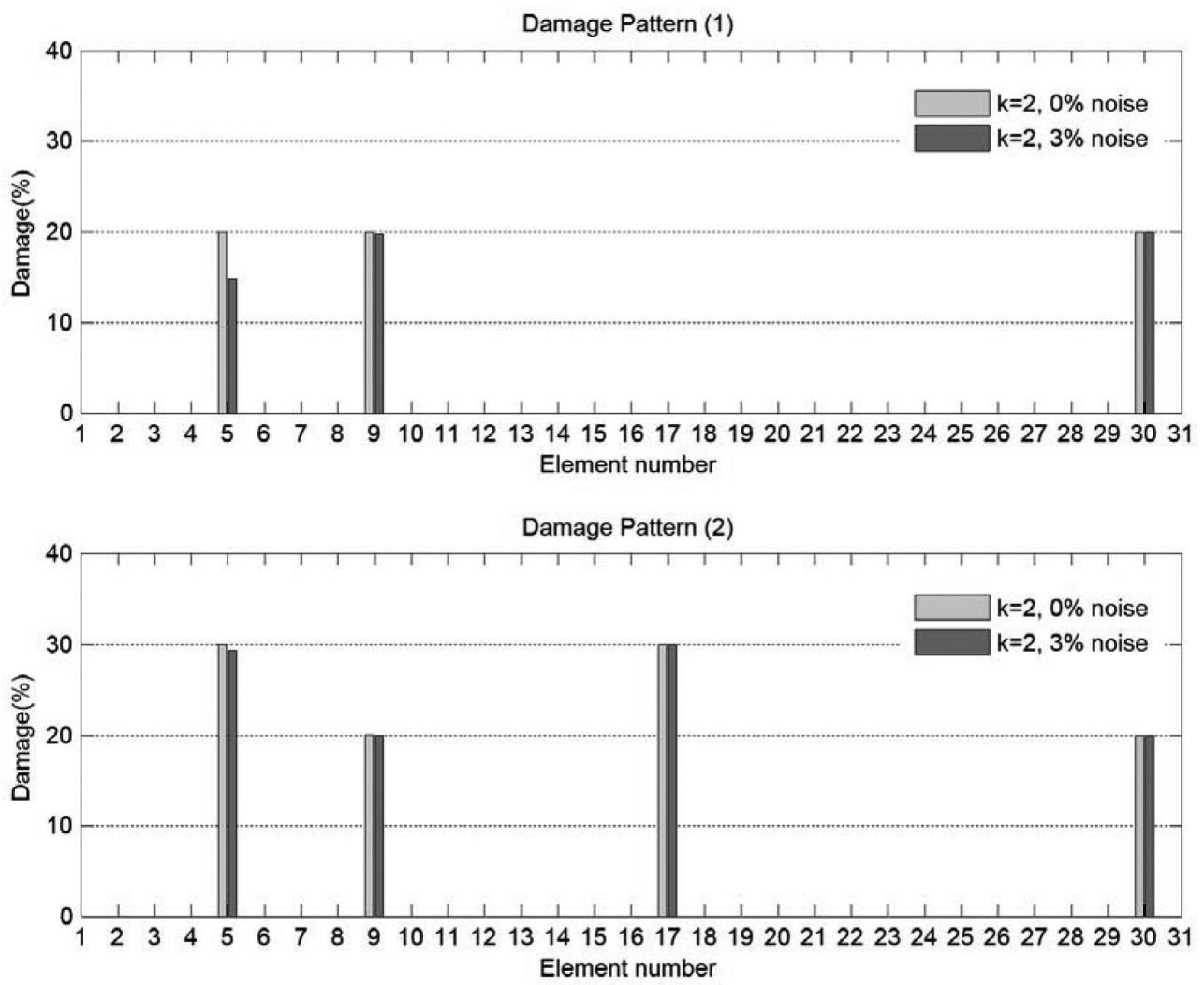

Fig. 10. Results of damage identification for two damage patterns of the plane steel truss.

\section{Conclusions}

In this paper, a method has been developed for the detection and estimation of damage in structures on the basis of the modal parameters of the damaged structure using an optimization problem. In this method, imperialist competitive algorithm is used to determine the damage in structures by optimizing a cost function.

Some of the advantages of the imperialist competitive algorithm are as follow: 
- Doesn't require derivative information,

- Simultaneously searches from a wide sampling of the cost function,

- Deals with a large number of variables,

- Is well suited for parallel computers,

- Optimizes variables with extremely complex cost function,

- Provides a list of optimum variables, not just a single solution, and

- Works with numerically generated data, experimental data, or analytical functions.

To validate the efficiency and applicability of the proposed method, a study on the damage detection was conducted using the benchmark of the IASC-ASCE Task Group on Structural Health Monitoring. The obtained results indicated that the proposed method is a strong and viable method to the problem of detection and estimation of damage in the structures. Moreover, the proposed method was applied to the numerical examples such as three-story plane steel frame and a plane steel truss. The results revealed high sensitivity of the proposed method to the damage.

\section{References}

[1] S.W. Doebling, C.R. Farrar, M.B. Prime and D.W. Shevitz, Damage identification and health monitoring of structural and mechanical systems from changes in their vibration characteristics: a literature review, Report LA-13070-MS, Los Alamos National Laboratory, 1996.

[2] A.K. Pandey, M. Biswas and M.M. Samman, Damage detection from changes in curvature mode shapes, Journal of Sound and Vibration 145 (1991), 321-332.

[3] Z.Y. Shi, S.S. Law and L.M. Zhang, Structural damage detection from modal strain energy change, Journal of Engineering Mechanics 126 (2000), 1216-1223.

[4] Z.Y. Shi, S.S. Law and L.M. Zhang, Improved damage quantification from elemental modal strain energy change, Journal of Engineering Mechanics 128 (2002), 521-529.

[5] T.-Y. Hus and C.-H. Loh, Damage diagnosis of frame structures using modified modal strain energy change method, Journal of Engineering Mechanics 134 (2008), 1000-1012.

[6] W. Bayissa, N. Haritos and S. Thelandersson, Vibration-based structural damage identification using wavelet transform, Mechanical Systems and Signal Processing 22 (2008), 1194-1215.

[7] R. Perera and R. Torres, Structural damage detection via modal data with genetic algorithms, Journal of Structural Engineering 132 (2006), 1491-1501.

[8] A.M. Raich and T.R. Liszkai, Improving the performance of structural damage detection methods using advanced genetic algorithms, Journal of Structural Engineering 133 (2007), 449-461.

[9] E. Atashpaz-Gargari and C. Lucas, Imperialist competitive algorithm: an algorithm for optimisation inspired by imperialistic competition, IEEE Congress on Evolutionary Computation, 2007.

[10] R. Rajabioun, E. Atashpaz-Gargari and C. Lucas, Colonial competitive algorithm as a tool for Nash equilibrium point achievement, Lecture Notes in Computer Science 5073 (2008), 680-695.

[11] E. Atashpaz-Gargari, F. Hashemzadeh, R. Rajabioun and C. Lucas, Colonial competitive algorithm, a novel approach for PID controller design in MIMO distillation column process, International Journal of Intelligent Computing and Cybernetics 1 (2008), 337-355.

[12] A. Khabbazi, E. Atashpaz-Gargari and C. Lucas, Imperialist competitive algorithm for minimum bit error rate beamforming, International Journal of Bio-Inspired Computation 1 (2009), 125-133.

[13] S.J. Dyke, D. Bernal, J.L. Beck and C. Ventura, An experimental benchmark problem in structural health monitoring, Proceeding of 3rd International Workshop on Structural Health Monitoring, Stanford, CA, 2001, 12-14.

[14] A. Sharifi and M.R. Banan, Energy index method: technique for identification of structural damages, Journal of Structural Engineering 134 (2008), 1061-1064.

[15] E.A. Johnson, H.F. Lam, L.S. Katafygiotis and J.L. Beck, Phase I IASC-ASCE structural health monitoring benchmark problem using simulated data, Journal of Engineering Mechanics 130 (2004), 3-15.

[16] http://wusceel.cive.wustl.edu/asce.shm. 

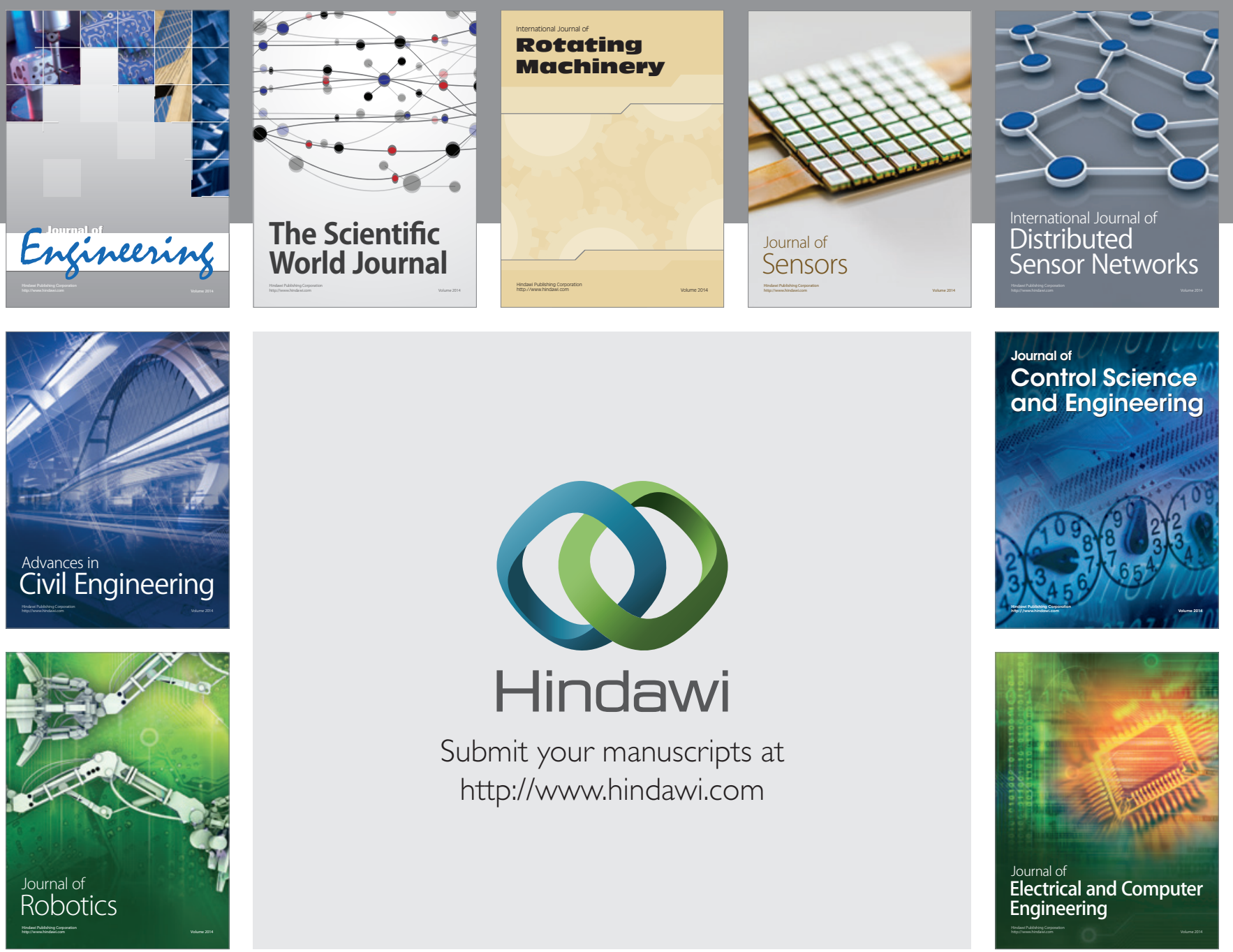

Submit your manuscripts at

http://www.hindawi.com
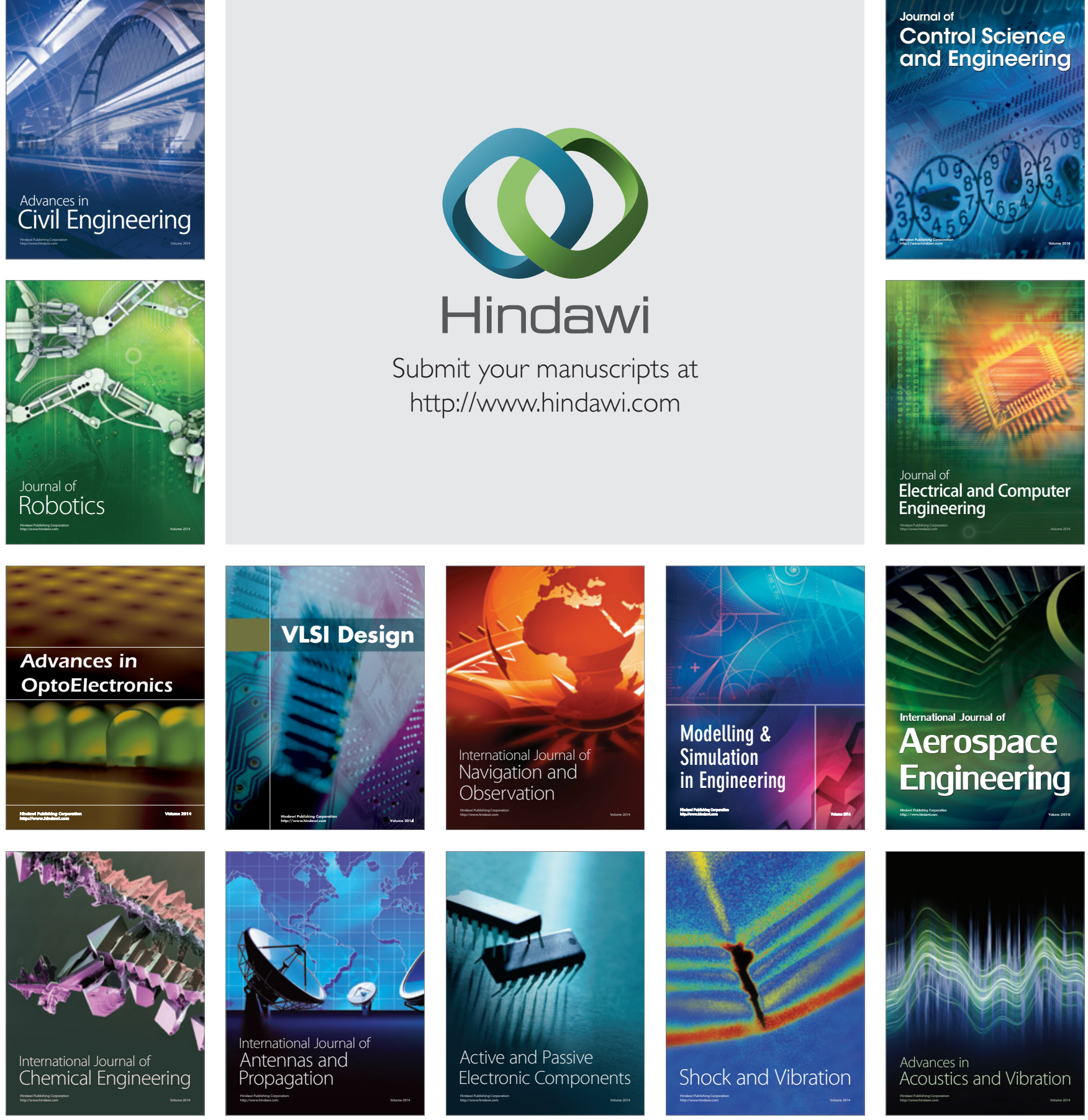